Thorax, 1980, 35, 9-18

\title{
Bronchoalveolar lavage in pulmonary fibrosis: comparison of cells obtained with lung biopsy and clinical features
}

\author{
P L HASLAM, C W G TURTON, B HEARD, A LUKOSZEK, J V COLLINS, \\ A J SALSBURY, AND M TURNER-WARWICK
}

From the Cardiothoracic Institute, Brompton Hospital, London

ABSTRACT Bronchoalveolar lavage, open lung biopsy, and cell extraction from the biopsy material have been studied in 21 symptomatic patients with progressive pulmonary fibrosis (18 with cryptogenic fibrosing alveolitis, fulfilling also the criteria for "usual interstitial pneumonia" (UIP), and three with rapidly progressive disease probably related to asbestos exposure). The total and differential cell counts between the three different samples have been compared as well as the influence on them of smoking and their correlation with steroid responsiveness and later progress. There was no correlation between semiquantitative scores of cell types observed within alveolar spaces and in alveolar walls and the differential or total cell counts obtained from extraction or lung lavage samples. There was, however, some correlation between differential counts obtained from lung lavage and extractions (neutrophils $\mathrm{p}<0.02$, eosinophils $\mathrm{p}<0.07$, lymphocytes $\mathrm{p}<0.08$ ) suggesting that lung lavage reflects the cellularity of the peripheral parts of the lung in patients without overt bronchial disease. Steroid responsiveness related to the percentage of lymphocytes found in extraction samples $(p<0.01)$ and was associated with a complementary fall in the percentage of macrophages $(p<0.02)$. There was no relationship between steroid response and the numbers of neutrophils or eosinophils in extracted samples. There was a trend towards increased numbers of lymphocytes in the lung wash in those patients responding to steroids. Those cases showing more rapid progression before starting treatment tended to have higher percentages of lymphocytes, neutrophils, or eosinophils in the lung lavage than more slowly deteriorating cases $(p<0.01)$. Follow-up studies showed that three cases having predominant lymphocytes in the lung lavage continued to do well while nine cases with predominant neutrophils or eosinophils or both showed a less satisfactory response to steroids and often deteriorated. Differential cell counts from biopsy extractions and lung lavage may give information additional to conventional light microscopy on the likelihood of steroid responsiveness as well as providing some measure of the activity of disease.

Cryptogenic fibrosing alveolitis (CFA) presents great problems in management because the prognosis is so variable. ${ }^{1-3}$ Thus while the median survival time in some recent large series of cases is about four years, $20(10 \%)$ of our own series of 209 cases and seven of $39(18 \%)$ of patients with usual interstitial pneumonia (UIP) in the series reported by Carrington et $a l^{2}$ were alive after 10 years.

Address for reprint requests: Professor M Turner-Warwick, Cardiothoracic Institute, Brompton Hospital, Fulham Road, London SW3 6HP.
It is well known that corticosteroids induce a substantial objective and subjective improvement in some patients but not in others. Patients with desquamative interstitial pneumonia (DIP) described by Liebow et $a l^{4}$ responded particularly well. Sixty-one per cent of 26 treated cases of DIP studied recently by Carrington $e t a l^{2}$ showed improvement. Patients with variable histological features of usual interstitial pneumonia (UIP) respond less well; only $11.5 \%$ of 26 carefully defined cases reported by Carrington et $a l^{2}$ improved. Dreisin et $a l^{5}$ showed that cases fulfilling 
the criteria for UIP but with greater cellularity and less fibrosis responded more frequently, thus confirming the earlier report by Scadding and Hinson. ${ }^{6}$

Using a semiquantitative analysis of histological features of 62 cases in which nearly half were asymptomatic at the time of the first radiograph, Wright $e t a l^{7}$ have shown a correlation between increased numbers of interstitial neutrophils, eosinophils, and lymphocytes and response to steroids.

A major problem in attempting to establish histological correlates with steroid responsiveness is the patchiness of the disease, where even open lung biopsy is likely to be unrepresentative of the whole. The technique of bronchoalveolar lavage samples inflammatory cells from more than one segment of lung and might therefore yield a more representative sample than histological sections of biopsy specimens.

The purpose of the present study was to compare yields of cells obtained from bronchoalveolar lavage fluid (referred to here as lung lavage) with those observed using semiquantitative histological methods on biopsy specimens and with quantitative counts of cells extracted from these specimens. The extraction studies were made to establish whether cells obtained by lung lavage reflect the cell population in the biopsy material, or whether the lavage sample contains a major component of cells derived from smaller airways.

The characteristics of broncho alveolar lavage fluid recovered from a larger number of patients with cryptogenic fibrosing alveolitis has been compared with those recovered from control populations in a separate report. ${ }^{8}$

\section{Methods}

\section{PATIENTS}

A total of 21 patients is reported in this study (table 1). There were 16 men and five womenow with a mean age of 48.9 years (range 34-62) Eighteen of the 21 were previously untreated consecutive patients fulfilling the criteria for cryptogenic fibrosing alveolitis ${ }^{9}$ and undergoing ${ }_{C}$ diagnostic lung biopsy.

Three additional cases with rapidly progressing pulmonary disease with asbestos exposure have ${ }^{2}$ been included because the diagnosis was in doubt, $\overrightarrow{0}$ treatment with corticosteroids was to be attempted,, and both lung biopsy and lung lavage had beenundertaken. These cases are identified separately@ throughout the text.

The lung lavage was undertaken within thea two weeks preceding the biopsy in 18 patients. In three the open biopsy had been performed a few months earlier at another hospital and the lavageo performed afterwards. Seven patients with $\mathrm{CFA}_{\supset}^{\Im}$ were smokers, five ex-smokers, and six non

Table 1 Clinical features

\begin{tabular}{|c|c|c|c|c|c|c|c|c|c|c|c|c|c|c|}
\hline & \multirow[t]{2}{*}{ Sex } & \multicolumn{2}{|c|}{$\begin{array}{l}\text { Age at Smoking } \\
\text { lavage history }\end{array}$} & \multirow{2}{*}{$\begin{array}{l}\text { Duration } \\
\text { of } \\
\text { symptoms } \\
(\mathrm{mo})\end{array}$} & \multirow{2}{*}{$\begin{array}{l}\text { Clinical } \ddagger \\
\text { dyspnoea }\end{array}$} & \multirow{2}{*}{$\begin{array}{l}\text { FEV } \\
\% \text { Pred }\end{array}$} & \multirow{2}{*}{$\begin{array}{l}\text { FVC } \\
\% \text { Pred }\end{array}$} & \multirow{2}{*}{$\begin{array}{l}\text { KCO } \\
\% \text { Pred }\end{array}$} & \multirow{2}{*}{ Profusion $†$} & \multirow[t]{2}{*}{ Zonest } & \multicolumn{4}{|c|}{ Steroid responses* } \\
\hline & & $(y r)$ & $(y r)$ & & & & & & & & Clinical & $\begin{array}{l}\text { Phys } \\
\text { FVC }\end{array}$ & $\begin{array}{c}\text { iological } \\
\mathrm{KCO}\end{array}$ & $\begin{array}{l}\text { Radio } \\
\text { logical }\end{array}$ \\
\hline \multicolumn{15}{|l|}{ Group 1} \\
\hline 1 & $\mathbf{F}$ & 39 & Non & 72 & 1 & 38 & 36 & 99 & $0 / 1$ & 3 & + & + & + & + \\
\hline 2 & $\mathbf{F}$ & 59 & Ex 15 & 60 & 1 & 60 & 53 & 52 & $2 / 3$ & 3 & + & + & + & + \\
\hline 3 & $\mathbf{F}$ & 50 & Non & 6 & 1 & 79 & 86 & 51 & $2 / 2$ & 2 & + & 0 & + & + \\
\hline 4 & $\mathbf{M}$ & 56 & Ex 1 & 48 & 2 & 44 & 77 & 33 & $2 / 2$ & 6 & + & 0 & 0 & + \\
\hline 5 & $\mathbf{F}$ & 58 & Non & 24 & 2 & 61 & 63 & 64 & $3 / 3$ & 4 & + & 0 & 0 & + \\
\hline 6 & $\mathbf{M}$ & 62 & Ex 2 & 24 & 2 & 66 & 73 & 68 & $2 / 1$ & 2 & + & 0 & 0 & + \\
\hline \multicolumn{15}{|l|}{ Group 2} \\
\hline 7 & $\mathbf{M}$ & 57 & S 50 & 60 & 2 & 74 & 74 & 81 & $1 / 1$ & 6 & + & + & 0 & 0 \\
\hline 8 & $\mathbf{M}$ & 54 & Ex 12 & 36 & 1 & 84 & 78 & 92 & $2 / 1$ & 5 & + & + & 0 & 0 \\
\hline 9 & $\mathbf{M}$ & 59 & S 10 & 48 & 2 & 40 & 76 & 25 & $3 / 2$ & 4 & + & 0 & 0 & 0 \\
\hline 10 & $\mathbf{M}$ & 42 & Non & 24 & 1 & 77 & 71 & 84 & $1 / 1$ & 2 & + & 0 & 0 & 0 \\
\hline \multicolumn{15}{|l|}{ Group 3} \\
\hline $11 \mathrm{~A}$ & $\mathbf{M}$ & 43 & Ex 1 & 24 & 1 & 71 & 74 & 89 & $2 / 1$ & 2 & 0 & 0 & + & + \\
\hline $12 \mathrm{~A}$ & $\mathbf{M}$ & 37 & Ex 2 & 42 & 2 & 81 & 81 & 80 & $1 / 0$ & 2 & 0 & 0 & 0 & + \\
\hline 13 & $\mathbf{M}$ & 60 & S 10 & 15 & 2 & 77 & 76 & 51 & $2 / 1$ & 4 & 0 & 0 & 0 & + \\
\hline 14 & $\mathbf{F}$ & 51 & S 20 & 80 & 2 & 82 & 78 & 50 & $1 / 2$ & 4 & 0 & 0 & + & 0 \\
\hline 15 & $\mathbf{M}$ & 49 & Non & 96 & 1 & 41 & 35 & 70 & $1 / 2$ & 6 & 0 & 0 & + & 0 \\
\hline 16 & $\mathbf{M}$ & 41 & S 30 & 60 & 0 & 108 & 92 & 84 & $0 / 1$ & 2 & 0 & 0 & 0 & 0 \\
\hline 17 & $\mathbf{M}$ & 64 & Ex 12 & 28 & 1 & 98 & 84 & 101 & $1 / 1$ & 1 & 0 & 0 & 0 & 0 \\
\hline 18 & $\mathbf{M}$ & 41 & Non & 12 & 1 & 66 & 59 & 66 & $2 / 2$ & 5 & 0 & 0 & 0 & 0 \\
\hline $\begin{array}{l}19 \text { A } \\
\text { Untreated }\end{array}$ & $\mathbf{M}$ & 45 & Ex 1 & 10 & 0 & 102 & 102 & 71 & $1 / 1$ & 3 & 0 & 0 & 0 & 0 \\
\hline 20 & $\mathbf{M}$ & 55 & S 40 & 30 & 0 & 108 & 112 & 57 & $1 / 1$ & 6 & - & - & - & - \\
\hline 21 & $\mathbf{M}$ & 59 & S 25 & 6 & 2 & 92 & 107 & 56 & $1 / 2$ & 5 & - & - & - & - \\
\hline
\end{tabular}

*See Methods for criteria; $\uparrow$ ILO/UC classification; $¥$ Grade $0-3 ; \mathbf{A}=$ asbestos exposure. 
smokers. Two of the 18 patients with cryptogenic fibrosing alveolitis had rheumatoid arthritis, three systemic sclerosis, and one had evidence of systemic lupus erythematosus.

A formal trial of cortocosteroids was subsequently undertaken in 19 patients (CFA 16, asbestosis three). Prednisone in a dose of 40-60 mgs was given for a minimum of four weeks and the patients readmitted for reassessment between four and six weeks. The exact dose of steroids was adjusted within this dose range according to weight and age, slightly smaller doses being given to women. The time of recall was also adjusted so that patients reporting a marked improvement within a week or two were recalled at one month for reassessment of the dose of steroids. Thus, the patients failing to show early improvement had a slightly longer period of treatment before assessment. This slight flexibility of programme was considered to be important in the interests of individual patients in view of the potential side effects. Progress was monitored by clinical, physiological, and radiographic measurements. A four-point clinical grading of dyspnoea before and after treatment was used to assess changes in breathlessness. Physiological measurements included static lung volumes, standard measurements of ventilation and measurement of the transfer factor for carbon monoxide (TLCO) and its adjustment for the volume of ventilated lung (KCO), using a helium dilution method to establish the lung volume $\left(V_{A}\right)$. In this report, the results are expressed as a percentage of values predicted for sex, age, and height. ${ }^{10}$.

Chest radiographs were read in random order using the ILO/UC system. ${ }^{11}$ Pairs of films were also compared for change, the order of the films being unknown to the reader.

\section{BRONCHOALVEOLAR LAVAGE}

This was performed after premedication with atropine under local anaesthetic using $4 \%$ lignocaine, through an Olympus fibreoptic bronchoscope. All patients received supplementary oxygen. The tip of the bronchoscope was wedged into the lateral basal segment of the right lower lobe and $60 \mathrm{ml}$ aliquots of normal saline, buffered to $\mathrm{pH} 7.0$ with $8.4 \%$ sodium bicarbonate introduced and aspirated. The mean volume introduced was $443 \mathrm{ml}$ with a range of $300-550 \mathrm{ml}$. About a third (mean $27 \%$ ) of the introduced fluid was retrieved (mean $123 \mathrm{ml}$, range $80-240 \mathrm{ml}$ ). The aspirated fluid was collected into a sterile siliconised graduated container and transported on ice immediately to the laboratories where it was divided into aliquots for the various studies.

The patients were informed about the nature and purpose of the investigation and their signed agreement obtained. An assessment of the discomfort of the procedure to the patients has been made. While two patients found it distressing, all of the others found it reasonably acceptable. The majority stated that they would have a repeat lavage if necessary.

\section{LUNG BIOPSY}

This was performed as an open procedure in 20 of the 21 cases. A small right lateral incision was made and one or two samples taken, usually from the right lower and middle lobes in the region of the greater fissure, the site of the biopsy being reasonably similar to the site of the lung lavage. The single case having a drill biopsy had this done on the right lower lobe. Biopsy of the tip of the lingula was particularly avoided in view of the well-known fact that changes in this area may be particularly advanced and unrepresentative.

\section{Laboratory procedures}

All technical procedures involving the handling of inflammatory cells whether obtained from lung lavage or lung biopsies were performed using siliconised or plastic utensils to minimise loss of cells by adherence, and sterile techniques were observed.

\section{LAVAGE FLUID}

The total volume of aspirated lavage fluid was noted. Cells in the fluid were collected by immediate low speed centrifugation at $300 \mathrm{~g}$ for 5 minutes at $4^{\circ} \mathrm{C}$ and washed three times with cold minimal essential medium (MEM) containing $25 \mathrm{mM}$ Hepes buffer (Gibco Bio-cult, code 237). The cells were counted in an Improved Neubauer Counting Chamber using $1 \%$ methyl violet in $1 \%$ acetic acid as the counting fluid and adjusted to a concentration of $1.25 \times 10^{6}$ cells per ml. For morphological examination, slide preparations were made in a Shandon Cytocentrifuge using $100 \mu \mathrm{l}$ aliquots of the $1.25 \times 10^{6} \mathrm{cell} / \mathrm{ml}$ suspensions and spinning at $300 \mathrm{~g}$ for 10 minutes. After fixation in methanol, the preparations were stained with a May Grünwald stain as used for differential white blood cell counting. Slides were examined separately by two observers, and a differential counting scheme devised according to the range of morphological variants identified. Differential counts were made from total counts of 500 cells in view of the complexity of mor- 
phological appearances. "Macrophages" were identified having variable appearances including clear or foamy cytoplasm, densely pigmented cytoplasmic inclusions, and multinucleate cells. Electron microscopy on all samples confirmed that the great majority of these large mononuclear cells had the characteristics of macrophages. Lymphocyte variants included small and large lymphocytes and occasionally those with lobulated nuclei. Polymorphonuclear leucocytes (neutrophils) and eosinophils were also identified, and numbers of ciliated and squamous epithelial cells and alveolar lining cells recorded. Not all of these cell types have been selected for inclusion in the tabulated data which for this reason does not always give a differential count total of $100 \%$. Other features such as degenerate cells (of which there were many in one or two patients), mucus and fibres were also noted if present.

\section{LUNG BIOPSY}

A part of the biopsy specimen was fixed in formalin, embedded in paraffin wax and sectioned, and stained with haematoxylin and eosin.

A systematic semiquantitative histological assessment of each biopsy specimen was made according to an agreed protocol. The frequency of each type of inflammatory cell type was assessed according to a four-point scale (grade $1=$ none, grade $2=$ occasional, grade $3=$ moderately common, grade $4=$ numerous). Counts were made of large mononuclear cells ("macrophages"), neutrophils, eosinophils, and lymphocytes. Separate counts were made of intra-alveolar and interstitial cells. The degree of wall fibrosis and the degree of disorganisation of lung architecture were also recorded on similar four-point scales.

\section{LUNG BIOPSY CELL EXTRACTION}

In 12 of the 17 open biopsies performed after bronchoalveolar lavage, there was sufficient material for cell extraction studies, without prejudice to the routine diagnostic histology. Part of the lung biopsy specimen (approximately 1 to 2 grams in weight), was transported immediately from the operating theatre to the laboratory in a sterile dry container on ice. The tissue was weighed and subjected to an extraction procedure designed to obtain inflammatory cells. This involved chopping the tissue finely with scissors in a minimal volume of MEM containing $25 \mathrm{mM}$ Hepes buffer, then agitating with a further $20 \mathrm{ml}$ of this medium on a haematocrit rotator at $37^{\circ} \mathrm{C}$ for a total period of 1 hour. At 20 minute intervals the heavy tissue fragments were allowed to sediment briefly under gravity and the clear medium containing extracted inflammatory cells: collected and replaced with fresh medium. Pipette $\overline{\bar{c}}$ expulsion of the tissue fragments was performect at each recovery stage to aid cell extraction. (The enzyme collagenase was not used in the extractiones procedure because of our findings in another study $\overrightarrow{0}$ that such treatment adversely affected the rosette- $\overrightarrow{-}$ forming ability of peripheral blood lymphocytes). $\vec{\sigma}$ The extracted cells were finally washed three times: in fresh medium employing low speed centrifuga $x$ tion at $300 \mathrm{~g}$ for 5 minutes at $4^{\circ} \mathrm{C}$. The cells wereer counted, and cytocentrifuge preparations made $\overrightarrow{0}$ and stained for morphological examination aso described above for cells in lavage fluids.

\section{STATISTICAL ANALYSES}

Group comparisons for smoking and steroid responsiveness have been made using the MannWhitney U test.

Correlations involving qualitative biopsy scores and quantitative counts for extractions and lavage have been made using Spearman's rank correlation coefficient.

\section{Results}

\section{LUNG LAVAGE}

\section{Total cell yields}

The total cell yields varied from $392.5 \times 10^{6}$ to $6 \cdot 1 \times 10^{6}$ cells. One patient had an exceptionally high cell count, six times greater than the mean foro the other 20 patients. His counts have therefore been excluded from the main analyses but will beg commented upon separately. The mean total celp. yield for the 20 patients was $64.9 \times 10^{6}$. Lavageo volumes recovered from each patient gave a range of 1.3 to $0.06 \times 10^{6} / \mathrm{ml}$ cells (mean $0.52 \times 10^{\circ}$ cells $/ \mathrm{ml}$ ). The total cell counts were greater in smokers compared to non-smokers $(p=0.03)$, the alleged ex-smokers holding an intermediate posi-n tion (fig 1). The same order of total cell counts was observed in those with CFA (mean $0.51 \times{ }^{N}$ $10^{6} / \mathrm{ml}$ ) and those with asbestos exposure (mean $0.53 \times 10^{6} / \mathrm{ml}$ ).

\section{Differential cell counts (fig 2)}

Large mononuclear cells ("macrophages") were the predominant cell type (mean $75.7 \%$, range $37.8 \%-98.4 \%$ ). The mean value was less in CFA $(62.7 \%)$ than for the three patients with asbestos? exposure but the number in the asbestos group was too small for statistical analysis.

Neutrophils were present in CFA ranging from $0.2 \%$ to $42.6 \%$ (mean $9.8 \%$ ); the three patientso 


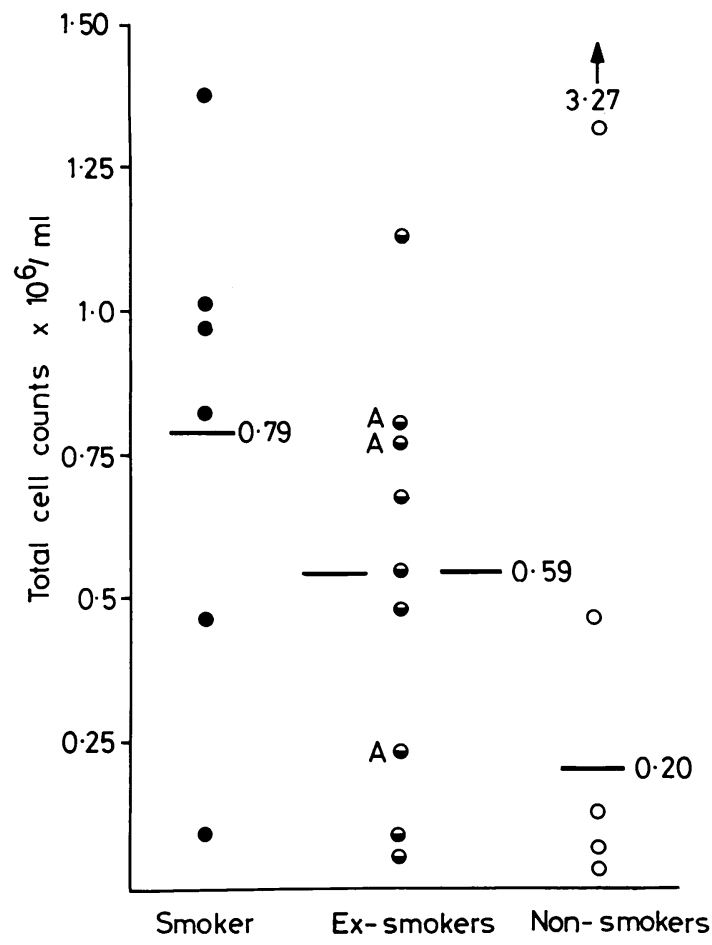

Fig 1 Total lung lavage cell count $\times 10^{6} / \mathrm{ml}$ in $17^{*}$ patients with cryptogenic fibrosing alveolitis and three with asbestos exposure $(A)$. - smoker; $\bigcirc$ ex-smoker; O non-smoker. ${ }^{*}$ Total cell count not performed in one patient. The exceptionally high value of $3 \cdot 27 \times$ $10^{\circ} / \mathrm{ml}$ has been excluded from the calculation of the mean in the group of non-smokers.

with asbestosis had counts of less than $4 \%$.

Although some individual patients who smoked had more than $20 \%$ neutrophils, there was no significant difference when smokers with CFA were compared with non-smokers.

Lymphocyte counts in CFA ranged from $0 \cdot 2 \%-$ $22 \%$ (mean $3.8 \%$ ) and for the asbestos group the mean was $1.9 \%$. The great majority of cells were small lymphocytes; in only two cases, both with CFA, additional large lymphocytes were seen $(0.02 \%$ and $1.3 \%$ respectively).

Eosinophil counts ranged from $0 \%-18 \%$ (mean $4.9 \%$ ) in CFA and a mean of $2.9 \%$ in three patients with asbestos exposure. Other types of cells including epithelial cells were included in the differential counts. Despite this there was a good correlation between the total numbers of each type of inflammatory cell $\times 10^{6} / \mathrm{ml}$ and the percentages of individual cells (lymphocytes $\mathrm{p}<0.05$; neutrophils $\mathrm{p}<0.01$; eosinophils $\mathrm{p}<0.01$ ). For this reason correlations of the differential cell counts

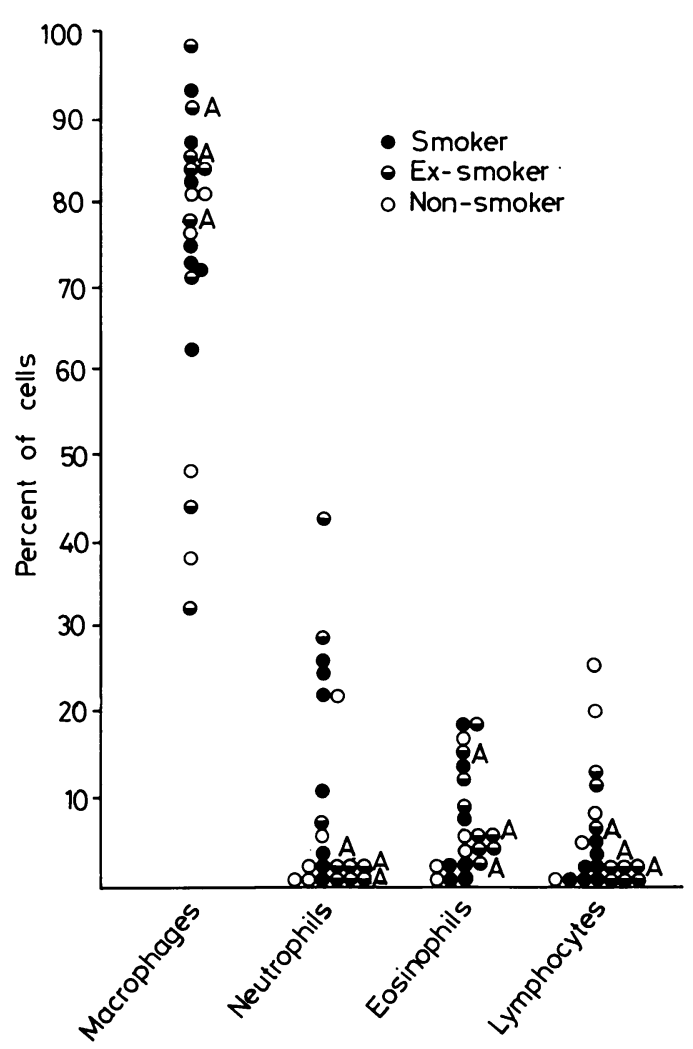

Fig 2 Differential lung lavage counts of inflammatory cells, expressed as percentages, in 18 patients with cryptogenic fibrosing alveolitis and in three with asbestos exposure $(A)$.

in the lung wash with those obtained from extraction studies or biopsy counts has been referred to percentage counts only. Correlations were not improved when cell counts $\times 10^{6} / \mathrm{ml}$ were considered.

Plasma cells were found in the lung washes of only four patients and always constituted less than $1 \%$ of the total counts.

\section{EXTRACTION STUDIES}

Correlation between the differential counts of inflammatory cells extracted from biopsy specimens and lung washes are shown in fig 3. A similar percentage of neutrophils were found in the extractions and washings and there is a significant correlation between the two $(p<0.02)$. A smaller percentage of eosinophils was obtained from the extractions than the lung washings but there is a possible correlation $(\mathrm{p}<0.07)$. Conversely, a higher percentage of lymphocytes was obtained from the extraction than the washing but again, 


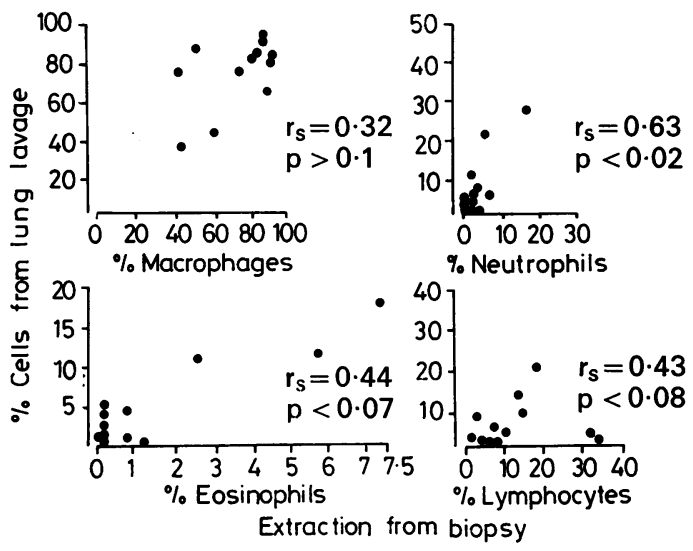

Fig 3 Correlation between the differential percentage counts for macrophages, neutrophils, eosinophils, and lymphocytes in lung washings and biopsy extractions. $P$ values derived from Spearman's rank correlation coefficients.

there is a suggestive correlation amongst these small numbers of cases $(\mathrm{p}<0.08)$.

\section{LUNG BIOPSIES}

In all patients with CFA, the biopsy appearances fulfilled the criteria for "usual interstitial pneumonia" (UIP) ${ }^{2}$ in varying stages of activity: none showed the appearances of typical desquamative interstitial pneumonia. Most patients showed considerable alveolar wall fibrosis as well as having many intra-alveolar mononuclear cells. Eighteen of 21 were graded 3 or 4 for both intra-alveolar mononuclear cells as well as fibrosis (fig 4a). The scores for neutrophils and eosinophils were generally lower, with a greater score for neutrophils in the intra-alveolar spaces than the interstitium $(p<0.05$, Wilcoxon matched-pairs signed ranks test). The lymphocyte scores tended to be higher with more in the interstitium $(p<0 \cdot 01)$. Figure 4 shows that the three patients with asbestosis also had a considerable interstitial inflammatory cell infiltrate.

The total score for each cell type (interstitial and intra-alveolar) has been used to correlate with the differential counts obtained by extracting cells from the biopsy specimen (table 2). A significant correlation was found between the extraction and biopsy score for lymphocytes $(p<0.03)$. There was no significant correlation between the biopsy scores and lung lavage for any inflammatory cell type. Neither could a significant correlation be found when biopsy scores for interstitial and intraalveolar cell counts were assessed individually.
Treatment with corticosteroids

The response to corticosteroids (and one patient on cyclophosphamide only) was assessed in $18 \frac{\bar{\sigma}}{\mathrm{c}}$ patients. There were six patients showing subjec- $\vec{\nabla}$ tive improvement of breathlessness as well as $\varrho$ objective radiographic and/or physiological improvement (group 1). There were four patients $\vec{\circ}$ showing subjective improvement only (group 2),

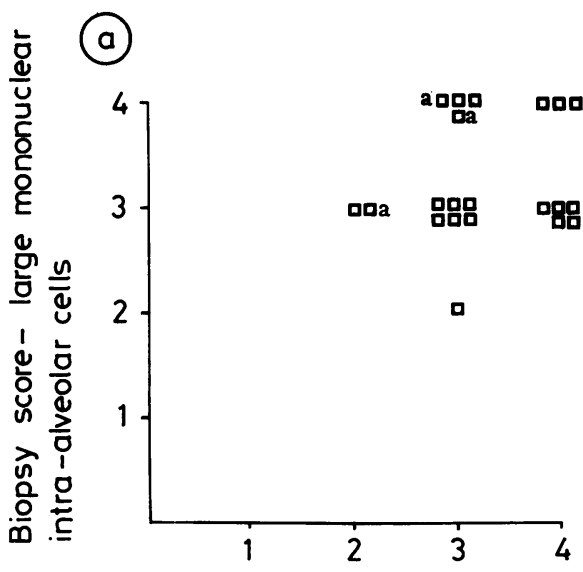

Biopsy score - wall tibrosis

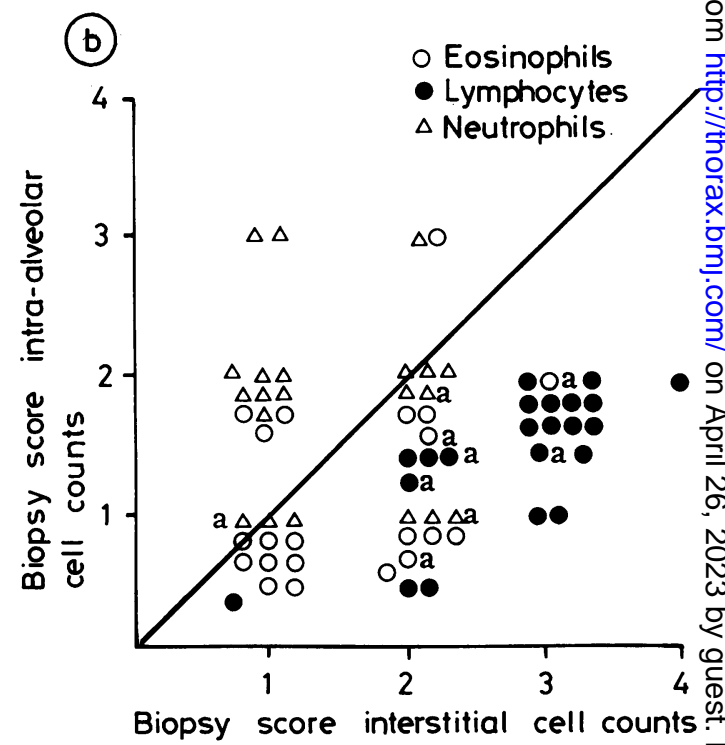

Fig 4 (a) Correlation between the biopsy score (grades 1-4) for alveolar wall fibrosis and for the numbers of large mononuclear intra-alveolar cells (mainly "macrophages"). (b) Correlation between the biopsy score (graded 1-4) for inflammatory cells in the "interstitium" and the intra-alveolar spaces. Cases with asbestos exposure marked (a). 
Table 2 Statistical significance of correlations between the percentage of inflammatory cells obtained from lung lavage and biopsy extractions and the percentage biopsy scores in 12 patients

\begin{tabular}{|c|c|c|c|c|c|c|c|c|}
\hline \multirow{2}{*}{$\begin{array}{l}\text { Comparison } \\
\text { Biopsyt versus } \\
\text { extraction }\end{array}$} & \multicolumn{2}{|c|}{ Macrophages } & \multicolumn{2}{|c|}{ Neutrophils } & \multicolumn{2}{|c|}{ Eosinophils } & \multicolumn{2}{|c|}{ Lymphocytes } \\
\hline & $\begin{array}{l}\mathbf{r}_{\mathbf{s}} \\
*\end{array}$ & $\mathbf{p}$ & $\begin{array}{l}\mathrm{r}_{\mathrm{s}} \\
0.32\end{array}$ & $\stackrel{p}{\text { NS }}$ & $\begin{array}{l}\mathrm{r}_{\mathrm{s}} \\
0.03\end{array}$ & $\stackrel{p}{N S}$ & $\begin{array}{l}\mathrm{rg}_{\mathrm{g}} \\
0.56\end{array}$ & $\begin{array}{l}p_{0.03}\end{array}$ \\
\hline $\begin{array}{l}\text { Biopsyt versus } \\
\text { lavage }\end{array}$ & $r_{s}$ & & $\begin{array}{l}r_{s} \\
0.32\end{array}$ & NS & $\begin{array}{l}r_{s} \\
0.007\end{array}$ & NS & $\begin{array}{l}\mathrm{rs} \\
0.29\end{array}$ & NS \\
\hline
\end{tabular}

$r_{\mathrm{s}}=$ Spearman's rank correlation.

NS $=p$ values $\equiv: 0 \cdot 1$.

* = biopsy ranking unsatisfactory as all cases graded 3 or 4 (see fig 4a).

$\dagger=$ total scores derived by summing interstitial and intra-alveolar scores for each cell type.

and eight (including the three patients with asbestos exposure) showing no improvement (group 3). There was no difference in the biopsy scores between the three groups either for individual inflammatory cell types or for the graded extent of fibrosis or lung destruction.

Figure 5a shows the differential count of lung extraction for lymphocytes neutrophils, and eosinophils in the steroid responders (groups 1 and 2) compared with the non-responders (group 3). The differential counts of lymphocytes are correlated with steroid responsiveness $(p<0.01)$ and this is associated with a significant complementary fall in the percentage of macrophages $(p<0.02)$. There was no relationship between the numbers of neutrophils or eosinophils in the extractions in relation to steroid responsiveness. The correlations with lung lavage is shown in fig 5b. Although these do not reach conventional significance, all of those with a lymphocyte count of $5 \%$ or greater responded to corticosteroid or immunosuppressant treatment. Eosinophils were found in all of the non-responders but in only about half of the responders $(p<0.07)$. There was no difference in the percentage of neutrophils found in the lung lavage when steroid responders and non-responders were compared.

\section{Progression rates}

The rate of progression before lung lavage (irrespective of steroid responsiveness) was assessed retrospectively in a crude way by dividing the patients into two groups: those whose subjective symptoms were unchanged over a six-month period before study and those who regarded themselves as increasingly breathless. There was a greater number of all types of inflammatory cell but proportionately fewer macrophages in the more rapidly progressive group (fig 6 ), $p<0.01$ ).

The progression over a minimum period of six months after steroids has been related to the type of inflammatory cell in the lung wash (table 3). The three patients with greater than $5 \%$ lympho- cytes with fewer than $10 \%$ neutrophils or $5 \%$ eosinophils all responded to steroids and improvement was maintained. Of the nine patients with an increase in neutrophils or eosinophils, four responded but improvement was not maintained in any patient and two deteriorated rapidly.
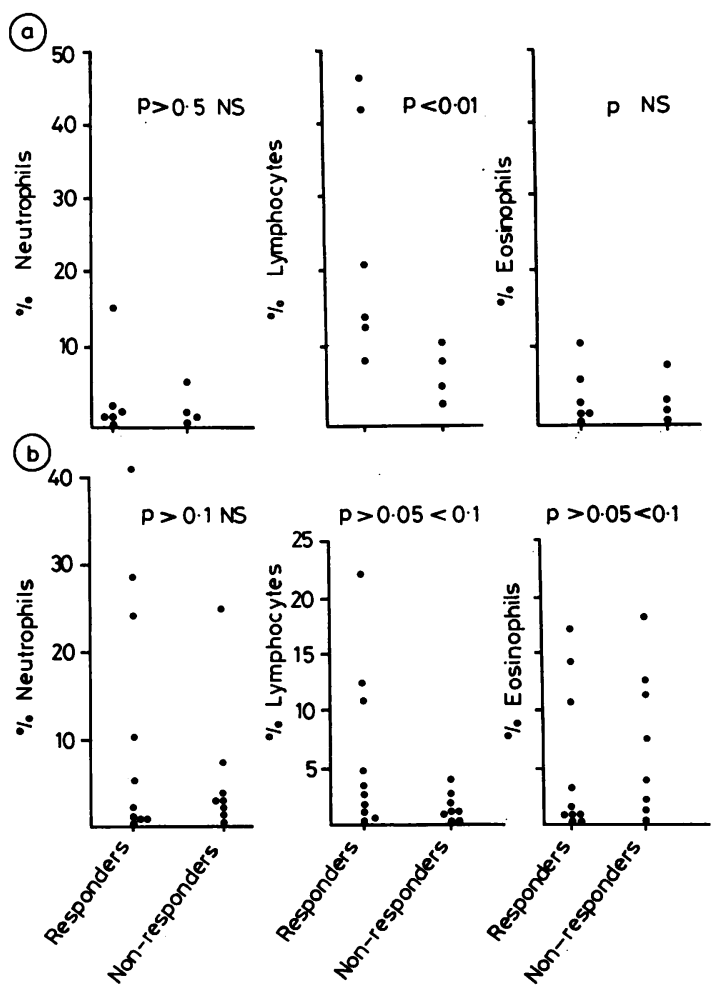

Fig 5 (a) Percentage counts of lymphocytes, neutrophils, and eosinophils in lung extractions from patients responding to corticosteroids (groups 1 and 2) compared with non-responders (group 3).

(b) Percentage counts of lymphocytes, neutrophils, and eosinophils in lung lavage from patients responding to cortocosteroids (groups 1 and 2) compared with non-responders (group 3). 


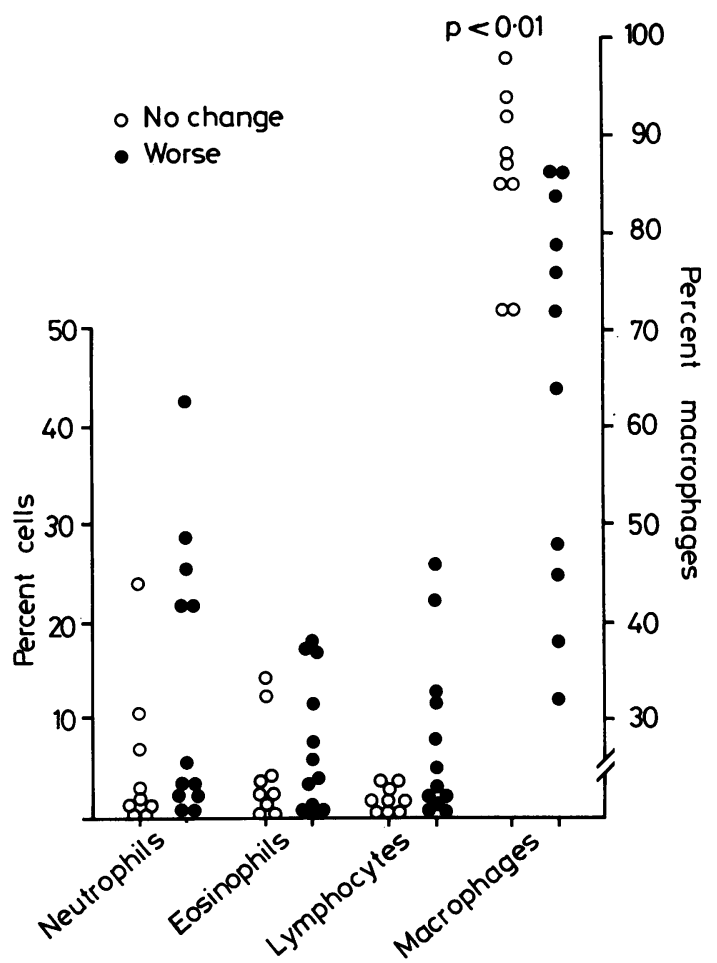

Fig 6 Percentage counts of inflammatory cells from lung lavage, comparing those with more rapid deterioration in breathlessness over six months before the study (๑) with those without increasing symptoms (O).

\section{Discussion}

The technique of bronchoalveolar lavage was originally introduced for the management of various clinical conditions, including alveolar proteinosis, cystic fibrosis, and intractable asthma. ${ }^{12}$ Only relatively recently has it been used to sample normal and diseased lungs using quanti-O tative methods. ${ }^{13-15}$ The method is of greato potential value because it is relatively non-invasive; $; \overline{\bar{N}}$ it can be done quickly under local anaesthetic ${ }_{\Omega}^{\mathbb{\Phi}}$ without damaging the lung, and can be repeatedळ if required. The cells obtained can be subjected to many different types of studies. For example, $:$ their morphology may be observed by light and $\vec{\omega}$ electron microscopy; and their characteristics can $\stackrel{5}{\circ}$ be observed in vitro when subjected to various $\vec{x}$ manipulations including their response to various drugs.

This report considers quantitative aspects of $\overrightarrow{0}$ cell counts from lavage and biopsy and the value응 of these counts as predictors of steroid responsive-ness and in relation to progression of disease.

A detailed analysis of the total and differential cell counts obtained from lung lavage samples in cryptogenic fibrosing alveolitis and other chronic interstitial diseases of the lung compared to con- $-\infty$ trols, is reported separately. ${ }^{8}$ The influence of ${ }^{\circ}$ smoking on the total cell numbers especially affecting the macrophages has been observed in our study but was not as marked as reported in normal healthy controls. ${ }^{131416}$ In contrast, theo number of lymphocytes and eosinophils appears $\stackrel{\Phi}{\Phi}$ to relate more closely to the presence of pul- $\overrightarrow{\vec{B}}$ monary disease. The number of neutrophils may 3 be influenced by both smoking and CFA and both? possibilities have to be considered. ${ }^{8}$

The studies reported here show some relation between differential counts of neutrophils ex-을 tracted from the biopsy specimens compared with $\widetilde{x}$ the lung lavage, supporting the suggestion that the latter indeed reflects changes in the peripheral parts of the lung in those patients who had noo evidence of bronchial disease. Similar conclusions $₹$ were drawn from a small number of studies re-음 ported by Weinberger et al. ${ }^{16}$ Fewer lymphocytes $>$ were found in the lung wash compared to the ex-ㅡㅡㄹ.

Table 3 Type of inflammatory cells in lung wash related to steroid responsiveness and subsequent progress

\begin{tabular}{|c|c|c|c|c|c|c|c|}
\hline Cell type & Number & $\begin{array}{l}\text { Steroid response } \\
\text { Group } 1\end{array}$ & Group 2 & Group 3 & $\begin{array}{l}\text { Progress over si } \\
\text { Improvement } \\
\text { maintained }\end{array}$ & $\begin{array}{l}\text { ix month } \\
\text { Stable }\end{array}$ & Worse \\
\hline \multirow{3}{*}{$\begin{array}{l}\text { Lymphocytes only }>5 \% \\
\text { Lymphocytes }>5 \% \\
\text { Neutrophils }>10 \% \\
\text { and/or eosinophils }>5 \% \\
\text { Neutrophils }>10 \% \\
\text { and/or eosinophils }>5 \%\end{array}$} & 3 & 2 & 1 & 0 & 3 & 0 & 0 \\
\hline & 2 & 1 & 0 & 1 & 1 & 0 & 1 \\
\hline & 9 & \multirow{2}{*}{$\begin{array}{l}1 \\
\text { (transient } \\
\text { improvement) } \\
2\end{array}$} & 3 & 5 & 0 & 3 & \multirow{2}{*}{$\begin{array}{l}6 \\
\text { ( } 2 \text { rapidly } \\
\text { worse) } \\
2 \\
\text { (slowly } \\
\text { progressing) }\end{array}$} \\
\hline No excess of any cell type & 5 & & 0 & 3 & 1 & 2 & \\
\hline Totals & 19 & 6 & 4 & 9 & 5 & 5 & 9 \\
\hline
\end{tabular}


traction, presumably reflecting the predominantly interstitial location of these cells. In spite of this, there was an overall trend of increase in lymphocytes and eosinophils in the washings in those with larger numbers in the extraction $(p<0.08)$; this becomes important when considering the response to corticosteroids. If patients have associated bronchial disease, the correlation between extraction and washings may be far less good and washings should not be assumed to reflect only acinar changes under all circumstances.

The overall histological appearances observed in this group of patients with cryptogenic fibrosing alveolitis corresponded to the criteria of "usual interstitial pneumonia" (UIP) ${ }^{2}$ in varying stages of activity and none fulfilled the criteria for "desquamative interstitial pneumonia" (DIP). Three cases were, however, regarded as mainly cellular with a high score for large mononuclear intra-alveolar cells and interstitial inflammatory cells, but not fulfilling the original description for DIP. Thus, it was not possible to achieve one of the original aims of this study, which was to attempt to distinguish UIP and DIP on lung lavage samples. The other 18 were mixed cellular and fibrotic, but if the criteria of Dreisin et $a l^{5}$ had to be used they would have fallen into their "cellular" category. These comparisons of our material with the histological classifications used by other workers is made to emphasise the difficulties which arise in comparing different studies where different terminology has been used.

The semiquantitative analysis of inflammatory cells in histological sections showed a significant correlation with the percentage of cells in the extraction sample for lymphocytes $(p<0.02)$ but not for neutrophils or eosinophils. A scale using only four points as well as the difficulties of counting accurately the numbers of inflammatory cells in tissue sections are both likely to have contributed to the lack of correlations with extraction or lung wash samples. The limitations experienced with biopsy material underlines the value of exploring other methods for quantifying the extent and type of inflammation present.

A notable feature in the present series was the high scores given both to the number of intraalveolar macrophages and the degree of wall fibrosis; thus a clear separation into more cellular and more fibrotic disease could not be made in our cases and it was therefore not possible to make an analysis of these types of biopsy appearances and steroid responsiveness. Results of the present study contrast with findings in another study reported from our group ${ }^{7}$ where the histology obtained by trephine biopsy was analysed by the same pathologist $(\mathrm{BH})$ using the same semiquantitative technique. In this larger series of 40 different patients there was a correlation between the score for interstitial neutrophils, eosinophils and lymphocytes and steroid responsiveness. The conflicting results in the two series may be caused by a number of factors: these include case selection, site and size of the biopsy sample, and limitations in precision of semiquantitative techniques. On the other hand the clinical assessment of steroid responsiveness is very imprecise and this too may have contributed to the different results in the two separate studies.

Analysis of cell counts in lung lavage samples in relation to steroid responses has been difficult in this relatively small series because of the very wide scatter of counts seen in individual patients. The problem is also complicated by the difficulties of assessing steroid responsiveness which, in most instances, is at best partial and in many was only observed in terms of subjective symptoms. In spite of these practical difficulties, the analysis has shown some useful indicators of responsiveness. There appeared to be a trend of higher lymphocyte counts and fewer patients with increased eosinophil counts amongst steroid responders compared with non-responders. The increase in lymphocyte counts obtained from the biopsy extractions among steroid responsive cases adds weight to the suggestion that lymphocyte counts in lung washings may be a useful procedure in planning management, especially perhaps in those cases in whom a biopsy is contraindicated. We also suggest that if biopsy is undertaken, quantitative counts of inflammatory cells obtained by extraction may provide more useful information predicting steroid responsiveness in cases with mixed histology than analysis of the tissue sections alone.

Assessment of activity of disease is important in deciding when to treat and how to titrate the dose of drugs used. Clinical, physiological, and radiographic parameters have proved crude yardsticks for this purpose especially in detecting quiescence of disease as opposed to improvement. Although the numbers of cases reported here are small and only provisional conclusions should be drawn, three indicators are worth noting. First, the few cases showing a predominant lymphocytic response reflected in the lung wash respond to steroids and tend to maintain good progress thereafter. Second, cases with an increase in neutrophils and eosinophils often fail to respond to steroids and sometimes deteriorate rapidly. Third, cases with relatively few inflammatory cells in the lung 
wash may be in a quiescent phase, neither improving on steroids nor deteriorating much during the follow-up period. Whether the predominance of lymphocytes rather than neutrophils and eosinophils reflects different stages in the disease or reflect different types of pathogenesis is unknown.

Finally, an explanation should be given for including three cases of pulmonary fibrosis and asbestos exposure. These were studied because, in spite of the exposure history, the diagnosis was in doubt. They all had widespread radiographic shadows, basal crackles, and finger clubbing characteristic equally of CFA or asbestosis. However, they showed an unusually rapid progression rate for asbestosis and all three were young patients under the age of 45 years. The biopsy was undertaken to assess cellularity before a trial of corticosteroids introduced in an attempt to arrest progression. In the event, asbestos bodies were found in the biopsy specimens but a substantial number of inflammatory cells were also found. All three cases showed moderate or marked increase in the number of intra-alveolar large mononuclear cells and only a minimal or moderate degree of fibrosis. None showed an increase in lung lavage lymphocytes and none responded to steroids. Whether their pulmonary disease can be attributed to asbestos exposure remains a matter for conjecture. Because of this the findings seemed to be worth reporting before better data are available in more typical cases of asbestosis.

Part of this study was supported by a generous grant from the Medical Research Council for which we are grateful. We are grateful to Miss $\mathbf{M}$ Rehan for her advice upon statistical analysis.

\section{References}

1 Stack BHR, Choo-Kang YFJ, Heard BE. The prognosis of cryptogenic fibrosing alveolitis. Thorax 1972; 27:535-42.

2 Carrington CB, Gaensler EA, Coutu RE, Fitzgerald MX, Gupta RG. Natural history and treated course of usual and desquamative interstitial pneumonia. N Eng J Med 1978; 298: 801-9.
3 Turner-Warwick M, Johnson A, Burrows B. Cryptogenic fibrosing alveolitis: clinical features and their influence on survival. Thorax 1980; $\frac{\bar{\sigma}}{\overline{0}}$ in press.

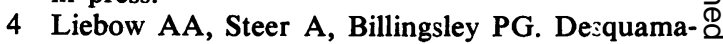
tive interstitial pneumonia. Am J Med 1965; 39:369-404.

5 Dreisin, RB, Schwartz MI, Theofilopoulos AN, $\vec{\circ}$ Stanford RE. Circulating immune complexes in $\overrightarrow{\vec{H}}$ the idiopathic interstitial pneumonias. $N E n g J \omega$ Med 1978; 298:353-7.

6 Scadding JG, Hinson KFW. Diffuse fibrosing alveolitis (diffuse interstitial fibrosis of the lungs). W Thorax 1967; 22:291-304.

7 Wright PH, Heard BE, Steel SJ, Turner-Warwick 6 M. Trephine biopsy histology in the management음 of cryptogenic fibrosing alveolitis. In preparation. -

8 Haslam PL, Turton CWG, Lukoszek A et al.c Bronchoalveolar lavage in interstitial lung dis-כ̆ orders. 1. Total and differential counts of lavage cells in cryptogenic fibrosing alveolitis. Thorax 1980 ; in press.

9 Turner-Warwick M, Haslam P. Antibodies in some chronic fibrosing lung diseases. 1. Nonorgan specific autoantibodies. Clin Allergy 1971;응 1:83-95.

10 Cotes JE. Lung function assessment and application in medicine. Third edition. Oxford: Black- م् wells, 1975.

11 International Union Against Cancer. Cincinnati classification of the radiographic appearances of $\frac{\mathrm{O}}{3}$ pneumoconinoses. Chest 1970; 58:57-67.

12 Ramirez RJ, Kieffer RF, Ball WC. Broncho pulmonary lavage in man. Ann Intern Med 1965; 63:819-28.

13 Reynolds HY, Newball HH. Fluid and cellularo milieu of the human respiratory tract. In: Kirkpatrick CH, Reynolds HY, eds. Immunologic and infectious reactions in the lungs. New York? Dekker, 1976; 3-28.

14 Daniele RP, Altose MD, Salisbury BG, Rowlands DT. Characterisation of lymphocyte sub-o populations in normal human lungs. Chest, Suppl 1975; 67:52-3.

15 Crystal RG, Fulmer JD, Roberts WC et al. Idiopathic pulmonary fibrosis: clinical, histologic, $N$ radiographic, physiologic, scintigraphic, cytologic and biochemical aspects. Ann Intern Med 1976; 85:769-86.

16 Weinberger SE, Kelman JA, Norton AE et al. Bronchoalveolar lavage in interstitial lung disease Ann Intern Med 1978; 89:459-66. 